\title{
ZASTUPLJENOST NAVIKE PUŠENJA KOD ADOLESCENATA
}

\author{
SMOKING HABIT IN ADOLESCENTS
}

\author{
Kosana Stanetić, Slavica Trifković Perić, Mirko Stanetić
}

\begin{abstract}
Sažetak
Uvod: Zloupotreba duvana u mnogim zemljama svijeta, kao i u našoj zemlji, poprima epidemijske razmjere. Posebno je izražena u populaciji mladih. Prema podacima Svjetske zdravstvene organizaciji (SZO) smatra se da danas u svijetu ima više od milijardu pušača.

Cilj: da se ispita zastupljenost pušenja kod učenika JU Gimnazija „Jovan Dučić“ u Doboju i uticaj socioekonomskih faktora na status pušenja učenika.

Metodologija: Istraživanje je provedeno među učenicima JU Gimnazija „Jovan Dučić“ u Doboju u periodu od marta do maja 2018. godine. Istraživanje je anonimno, a svim učenicima su ponuđena dva anketna upitnika: upitnik o socioekonomskom statusu (pol, dob, status porodice, obrazovanje roditelja, finansijska situacija porodice) i upitnik o upotrebi duvana.

Rezultati: Istraživanjem je obuhvaćeno 255 učenika, 38\% muškog i 62\% ženskog pola. Od ukupnog broja ispitanika, 16.08\% je izjavilo da konzumira cigarete (14 ženskog i 27 muškog pola). Najveći broj anketiranih učenika je počeo konzumirati cigarete sa 16 i više godina ( 19 ili 46,34\%). Muškarci u većem postotku konzumiraju aktivno cigarete između $14-15$ godine $i$ sa 16 i više godina u odnosu na žene, što je statistički značajno $(p=001)$. Učenici, čiji prijatelji puše, statistički značajno $(p=0.000)$ češće konzumiraju cigarete u odnosu na učenike čiji su prijatelji nepušači.

Zaključak: Adolescenti su rizična grupa za početak upotrebe duvana. Timovi porodične medicine bi trebalo da posvete veću pažnju u prevenciji pušenja, posebno kod ove osjetljive populacije.
\end{abstract}

Ključne riječi: pušenje, adolescenti, faktor rizika, mjere prevencije

\section{UVOD}

Pušenje se definiše kao uživanje duvana udisanjem dima zapaljenog duvanskog lišća u cigareti, cigari ili luli (1). Zloupotreba duvana je u stalnom je porastu $\mathrm{u}$ cijelom svijetu, tako da predstavlja ne samo medicinski nego i socioekonomski problem. Najviše su pogođene zemlje u tranziciji, među kojima se nalazi i naša zemlja (2). Prema Svjetskoj zdravstvenoj organizaciji (SZO) smatra se da danas ima više od milijardu pušača. Godišnje od posljedica pušenja umire 5 miliona ljudi. Pušenje duvana drugi je vodeći uzrok smrtnosti i četvrti zdravstveni faktor rizika u svijetu. Odgovorno je za oko 30\% svih malignih oboljenja, za $90 \%$ svih tumora respiratornog sistema i $40 \%$ svih smrti zbog koronarnih bolesti $(3,4)$.

Zavisnost od duvana vezuje se kako za genetske tako i za socijalne i psihičke faktore. Međutim, u prvom redu je to psihička zavisnost, koja je najčešće jakog inteziteta. Uglavnom osobe konzumiranje cigareta povezuju sa osjećajem ugode, dok drugi puše zbog prevladavanja stresa. Adolescenti pušenje doživljavaju kao zrelost i slobodu. Pušači koji su počeli sa konzumiranjem duvana u pubertetu navode da je to bio uticaj okoline (5).

Duvan je tjelesni otrov koji sadrži veliki broj štetnih sastojaka, a najznačajniji od njih su alkaloidi nikotina i nornikotina. Nikotin je najsnažnija komponenta i odgovoran je za stvaranje zavisnosti, djeluje tako što oslobađa neurotransmiter dopamin. $\mathrm{U}$ početku dovodi do osjećaja smirenosti i opuštanja, a kasnije do depresivnosti i zavisnosti (6).

Zdravstveni problemi pušača u početku nisu izraženi, sa godinama počinje postepen razvoj zdravstvenih tegoba koje su najizraženije kod respiratornog sistema. Pušenje se vezuje za nastanak hronične opstruktivne bolesti pluća, karcinomom pluća i usne duplje, zatim karcinoma mokraćne bešike i jednjaka, bolesti koje su vezane za kardiovaskularni sistem (ateroskleroza) (7). 
U Bosni i Hercegovini (BiH) ne postoji jedinstveno istraživanje o pušenju kod adolescenata, već je provedeno odvojeno za Federaciju Bosne i Hercegovine (FBiH) i Republiku Srpsku (RS). Prema The Europen School Survey Project on Alcohol and Other Drugs (ESPAD) studiji iz 2011. godine u posljednjih 30 dana u $\mathrm{FBiH}$ pušilo $31 \%$ adolescenata, a u Republici Srpskoj 15\% (8,9).

\section{CILJEVI RADA}

Cilj rada je da se ispita upotreba duvana kod učenika JU Gimnazija „Jovan Dučić“ u Doboju. Ostali ciljevi istraživanja: uporediti dobijene rezultate u odnosu na uzrast; uporediti dobijene podatke o rizičnom ponašanju u odnosu na pol, status porodice, obrazovanje roditelja i finansijsku situaciju porodice; dobijene rezultate uporediti sa rezultatima drugih sličnih istraživanja u zemlji i svijetu.

\section{METODOLOGIJA}

Istraživanje je sprovedeno anonimnim anketiranjem učenika JU Gimnazija „Jovan Dučićc u Doboju u periodu od marta do maja 2018. godine. Anketiranje je provedeno u prostorijama škole na časovima odjeljenske nastave u prisustvu razrednog starješine. Za ispitivanje dobijena je saglasnost direktora navedene ustanove (JU Gimnazija „Jovan Dučić“" Doboj, broj protokola 104-1/2018).

Svim učenicima škole ponuđena je anonimna anketa sa pitanjima o upotrebi duvana. Anketni upitnik se sastoji od osam pitanja. Pitanja su se odnosila na to koliko lako dolaze do cigareta, kada su aktivno počeli sa konzumiranjem cigareta i zbog čega, koliko njihovih prijatelja konzumira cigarete $\mathrm{i}$ koliki je rizik na zdravlje konzumirajem cigareta, gdje su zaokruživali jedan od više ponuđenih odgovora. Više odgovora mogli su zaokružiti na pitanje da li neko u njihovoj porodici konzumira cigarete.

U socioekonomskim dijelu ankete pitanja su se odnosila na pol ispitanika, godinu rođenja i razred. Učenici su se izjašnjavali o obrazovanju roditelja (otac/ majka), kao i statusu porodice (da li žive sa oba ili jednim roditeljom ili ne žive sa roditeljima), kao i finansijskom situacijom u porodici (loša, osrednja, dobra i odlična).

Podaci prikupljeni anketom su uneseni u Excel bazu podataka i statistički obrađeni. Korišten je Hi kvadrat test, gdje statistička značajnost bila $\mathrm{p}<$ 0.05. Dobijeni podaci o rizičnom ponašanju su upoređivani u odnosu na pol, dob, status porodice, obrazovanje roditelja i finansijsku situaciju porodice.

\section{REZULTATI}

Anketirano je 255 učenika od toga 157 (61.6\%) ženskog i 98 (38.4\%) muškog pola. Najmlađi ispitanik imao je 15 godina, a najstariji 20 godina.

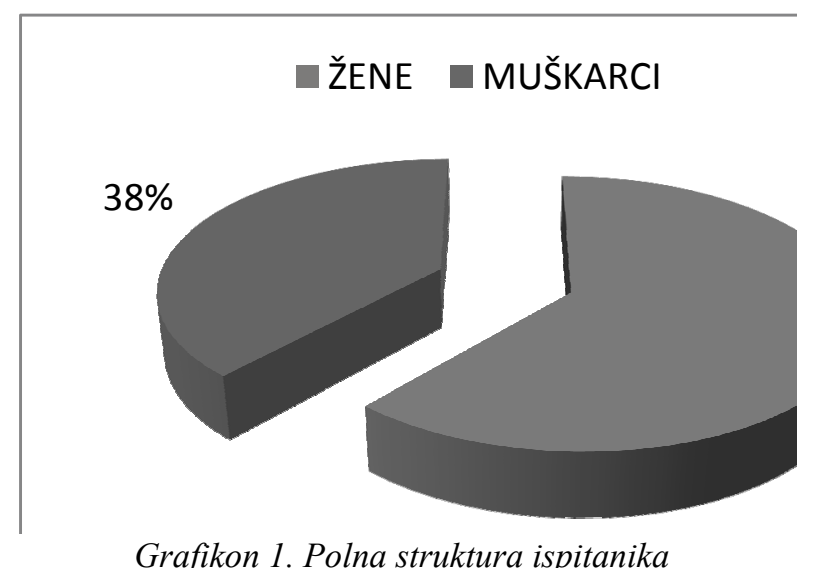

U grafikonu 2 je prikazana starosna struktura ispitivanih učenika.

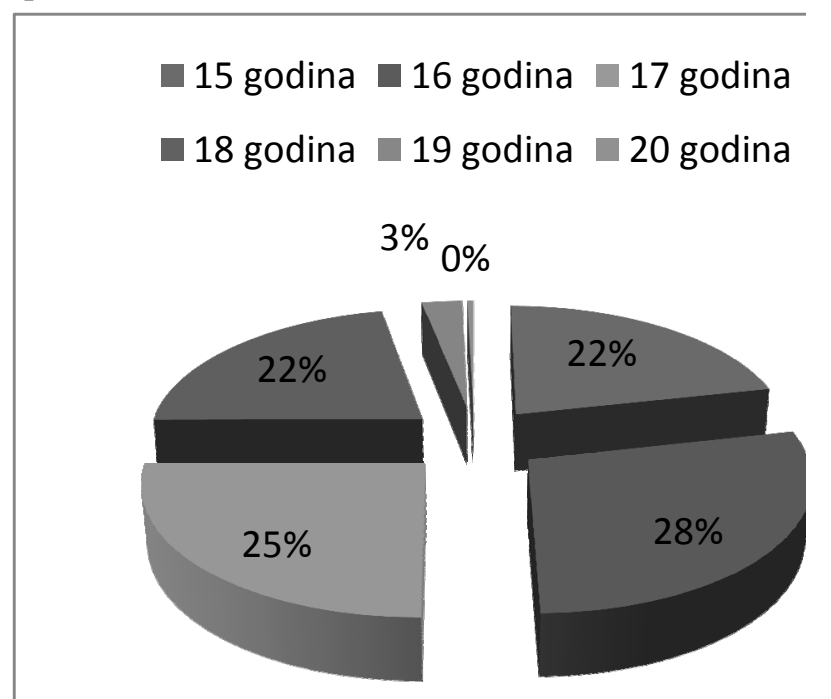

Grafikon 2. Starosna struktura ispitanika

Rezultati istraživanja su pokazali da je do cigareta vrlo lako dolazilo je 98 (38.4\%) učenika, a nemoguće bilo je za 18 (7.1\%) učenika. Većina anketiranih učenika (205 ili 83.92\% učenika) nikada 
nije konzumiralo cigarete, dok cigarete konzumira $16.08 \%$ učenika. Učenici najčešće konzumiraju cigarete zato što se osjećaju bolje nakon nesuglasica sa roditeljima ili prijateljima. Majka je konzumirala češće cigarete $u$ odnosu na ostale članove porodice. Samo kod 24 učenika niko od prijatelja ne konzumira cigarete. Da cigarete imaju štetno dejstvo na zdravlje izjavilo je 193 učenika (Tabela 1).

Tabela 1. Podaci o konzumiranje cigareta među adolescentima

\begin{tabular}{|c|c|c|c|}
\hline Pitanja & Ponuđeni odgovori & $\begin{array}{l}\text { Broj } \\
\text { odgovora } \\
\%\end{array}$ & $\begin{array}{l}\text { Ukupno } \\
\text { ispitanika } \\
\text { N }\end{array}$ \\
\hline \multirow{6}{*}{ Koliko Vam je teško da dođete do cigareta ukoliko bi to željeli? } & Nemoguće & $18(7.1)$ & \multirow{6}{*}{237} \\
\hline & Vrlo teško & $3(1.2)$ & \\
\hline & Prilično teško & $8(3.1)$ & \\
\hline & Prilično lako & $42(16.5)$ & \\
\hline & Vrlo lako & $98(38.4)$ & \\
\hline & Ne znam & $68(26.7)$ & \\
\hline \multirow{7}{*}{ Koliko često ste pušili cigarete u zadnjih mjesec dana? } & Ni jednom & $206(80.4)$ & \multirow{7}{*}{246} \\
\hline & 1 cigareta mjesečno & $6(2.4)$ & \\
\hline & 1 cigareta sedmično & $2(0.8)$ & \\
\hline & $1-5$ cigareta dnevno & $6(2.4)$ & \\
\hline & $6-10$ cigareta dnevno & $12(4.7)$ & \\
\hline & $11-20$ cigareta dnevno & $10(3.9)$ & \\
\hline & $\begin{array}{l}\text { Više od } 20 \text { cigareta } \\
\text { dnevno }\end{array}$ & $4(1.6)$ & \\
\hline \multirow{6}{*}{ Kada ste aktivno počeli da konzumirate cigarete? } & Nikada & $205(80.4)$ & \multirow{6}{*}{246} \\
\hline & 9 i manje godina & $2(0.8)$ & \\
\hline & $10-11$ godina & $0(0.0)$ & \\
\hline & $12-13$ godina & $2(0.8)$ & \\
\hline & $14-15$ godina & $18(7.3)$ & \\
\hline & 16 i više godina & $19(7.7)$ & \\
\hline \multirow{3}{*}{ Zbog čega ste počeli da konzumirate cigarete? } & 1. & $5(2.0)$ & \multirow{3}{*}{41} \\
\hline & 2. & $24(9.4)$ & \\
\hline & 3. & $12(4.7)$ & \\
\hline \multirow[t]{2}{*}{ Da li Vam se događalo da mjesečni džeparac potrošite na cigarete? } & $\mathrm{Da}$ & $14(5.5)$ & \multirow[t]{2}{*}{50} \\
\hline & $\mathrm{Ne}$ & $36(14.1)$ & \\
\hline \multirow{3}{*}{ Da li neko u Vašoj porodici konzumira cigarete? } & Otac & $72(28.2)$ & \multirow{3}{*}{255} \\
\hline & Majka & $81(31.8)$ & \\
\hline & Brat/ Sestra & $28(11.0)$ & \\
\hline \multirow{5}{*}{ Koliko tvojih prijatelja konzumira cigarete? } & Niko & $24(9.4)$ & \multirow{5}{*}{253} \\
\hline & Malo & $68(26.7)$ & \\
\hline & Nekoliko & $100(39.2)$ & \\
\hline & Većina & $51(20.0)$ & \\
\hline & Svi & $10(3.9)$ & \\
\hline \multirow{4}{*}{$\begin{array}{l}\text { Koliko je po Vašem mišljenju rizik da ljudi sebi naštete } \\
\text { konzumiranjem cigareta? }\end{array}$} & Nema rizika & $8(3.1)$ & \multirow{4}{*}{252} \\
\hline & Mali rizik & $22(8.6)$ & \\
\hline & Veliki rizik & $193(75.7)$ & \\
\hline & Ne znam & $29(11.4)$ & \\
\hline
\end{tabular}

$1 *$ da bih skrenuo pažnju na sebe i bio „važniji u društvu“; $2^{*}$ na taj način se osjećao bolje nakon nesuglasica sa roditeljima, prijateljima, bio smireniji; $3 *$ zato što su me drugi nagovorili samo da probam

Od 246 ispitanika,koji su odgovorili na pitanje o konzumiranju cigareta, ukupno 205 (136 ili 90.7\% žena i 69 ili $71.9 \%$ ) muškaraca) je izjavilo da nije konzumiralo cigarete, dok je 41 ispitanik (16.09\%) izjavio da konzumira cigarete. Većina učenika, koji konzumiraju cigarete, puše prosječno 6 - 10 ili 1020 cigareta dnevno. Muškarci u većem postotku konzumiraju aktivno cigarete između $14-15$ godine i sa 16 i više godina u odnosu na žene, što je statistički značajno $(\mathrm{p}=001)$ (Tabela 2$)$. 
Tabela 2. Odnos pola i godina na vrijeme početka konzumiranja cigareta

\begin{tabular}{|c|c|c|c|c|c|}
\hline \multirow{3}{*}{ Pitanje } & \multirow{3}{*}{$\begin{array}{l}\text { Ponuđeni } \\
\text { odgovori }\end{array}$} & \multicolumn{2}{|l|}{ Pol } & \multirow{3}{*}{$\begin{array}{l}\text { Ukupno ispitanika po odgovorima }(\mathrm{N}) \text { i } \\
\text { postotak }(\%)\end{array}$} & \multirow{3}{*}{$\mathbf{p}^{*}$} \\
\hline & & M & $\check{Z}$ & & \\
\hline & & $\mathrm{N}(\%)$ & $\mathrm{N}(\%)$ & & \\
\hline \multirow{6}{*}{$\begin{array}{l}\text { Kada ste aktivno } \\
\text { konzumirate cigarete? }\end{array}$} & Nikada & $\begin{array}{l}69 \\
(71.9)\end{array}$ & $\begin{array}{l}136 \\
(90.7)\end{array}$ & $205(83.3)$ & \multirow{7}{*}{.001} \\
\hline & 9 i manje godina & $2(2.1)$ & $0(0.0)$ & $2(0.8)$ & \\
\hline & $10-11$ godina & $0(0.0)$ & $0(0.0)$ & $0(0.0)$ & \\
\hline & $12-13$ godina & $2(2.1)$ & $0(0.0)$ & $2(0.8)$ & \\
\hline & $14-15$ godina & $\begin{array}{l}13 \\
(13.5)\end{array}$ & $5(3.3)$ & $18(7.3)$ & \\
\hline & 16 i više godina & $\begin{array}{l}10 \\
(10.4)\end{array}$ & $9(6.0)$ & $19(7.7)$ & \\
\hline \multicolumn{2}{|c|}{ Ukupno ispitanika prema polu (N) i postotak (\%) } & $\begin{array}{l}96 \\
(100)\end{array}$ & $\begin{array}{l}150 \\
(100)\end{array}$ & $246(100)$ & \\
\hline
\end{tabular}

*statistički značajno na nivou $\mathrm{p}<0.05$

Rezultati istraživanja su pokazali da status porodice nije statistički značajno uticao na dob kada su ispitanici počeli konzumirati cigarete $(\mathrm{p}=0.143)$. Većina ispitanika je počela pušiti u dobi od 14 i više godina, bez obzira na status porodice (Tabela 3 ).

Tabela 3. Odnos statusa porodice i godina ispitanika kada je počeo sa konzumiranjem cigareta

\begin{tabular}{|c|c|c|c|c|c|}
\hline \multirow{3}{*}{ Pitanje } & \multirow{3}{*}{$\begin{array}{l}\text { Ponuđeni } \\
\text { odgovori }\end{array}$} & \multicolumn{2}{|c|}{ Status porodice } & \multirow{3}{*}{$\begin{array}{l}\text { Ukupno ispitanika prema } \\
\text { odgovrima }(\mathrm{N}) \text { i postotak }(\%)\end{array}$} & \multirow{3}{*}{$\mathbf{p}^{*}$} \\
\hline & & $\begin{array}{l}\text { Živi sa oba } \\
\text { roditelja }\end{array}$ & $\begin{array}{l}\text { Živi sa jednim } \\
\text { roditeljem }\end{array}$ & & \\
\hline & & $\mathrm{N}(\%)$ & $\mathrm{N}(\%)$ & & \\
\hline \multirow{6}{*}{$\begin{array}{l}\text { Kada ste aktivno počeli da } \\
\text { konzumirate cigarete? }\end{array}$} & Nikada & $175(83.7)$ & $30(81.1)$ & $205(83.3)$ & \multirow{7}{*}{.143} \\
\hline & $\begin{array}{l}9 \text { i manje } \\
\text { godina }\end{array}$ & $2(1.0)$ & $0(0.0)$ & $2(0.8)$ & \\
\hline & $10-11$ godina & $0(0.0)$ & $0(0.0)$ & $0(0.0)$ & \\
\hline & $12-13$ godina & $2(1.0)$ & $0(0.0)$ & $2(0.8)$ & \\
\hline & $14-15$ godina & $12(5.7)$ & $6(16.2)$ & $18(7.3)$ & \\
\hline & $\begin{array}{l}16 \text { i više } \\
\text { godina }\end{array}$ & $18(8.6)$ & $1(2.7)$ & $19(7.7)$ & \\
\hline \multicolumn{2}{|c|}{$\begin{array}{l}\text { Ukupno ispitanika prema statusu porodice }(\mathrm{N}) \text { i } \\
\text { postotak }(\%)\end{array}$} & $209(100)$ & $37(100)$ & $246(100)$ & \\
\hline
\end{tabular}

*statistički značajno na nivou $\mathrm{p}<0.05$

Finansijska situacija u porodici nije statistički značajno $(\mathrm{p}=0.810)$ uticala na konzumiranje cigareta. Učenici su izjavili da do cigareta mogu doći prilično lako u 42 (17.7\%) slučajeva, vrlo lako u 68 (41.4\%) slučajeva, dok je za 18 (7.6\%) ispitanika to je bilo nemoguće (Tabela 4).

Tabela 4. Uticaj finansijske situacije na konzumiranje cigareta

\begin{tabular}{|c|c|c|c|c|c|c|c|}
\hline \multirow[b]{3}{*}{ Pitanje } & \multirow[b]{3}{*}{$\begin{array}{l}\text { Ponuđeni } \\
\text { odgovori }\end{array}$} & \multicolumn{4}{|c|}{ Finansijska situacija u porodici } & \multirow{3}{*}{$\begin{array}{l}\text { Ukupno ispitanika prema } \\
\text { odgovorima }(\mathrm{N}) \text { i postotak }(\%)\end{array}$} & \multirow[b]{3}{*}{$p^{*}$} \\
\hline & & Loša & Osrednja & Dobra & Odlična & & \\
\hline & & N (\%) & N (\%) & N (\%) & N (\%) & & \\
\hline \multirow{5}{*}{$\begin{array}{l}\text { Koliko Vam je teško da dođete } \\
\text { do cigareta ukoliko bi to željeli? }\end{array}$} & Nemoguće & $0(0.0)$ & $3(8.1)$ & $\begin{array}{l}13 \\
(9.0)\end{array}$ & $2(4.1)$ & $18(7.6)$ & \multirow{5}{*}{.810} \\
\hline & Vrlo teško & $0(0.0)$ & $1(2.7)$ & $2(1.4)$ & $0(0.0)$ & $3(1.3)$ & \\
\hline & Prilično teško & $0(0.0)$ & $3(8.1)$ & $5(3.5)$ & $0(0.0)$ & $8(3.4)$ & \\
\hline & Prilično lako & $\begin{array}{l}2 \\
(28.6)\end{array}$ & $8(21.6)$ & $\begin{array}{l}25 \\
(17.4)\end{array}$ & $7(14.3)$ & $42(17.7)$ & \\
\hline & Vrlo lako & $\begin{array}{l}3 \\
(42.9)\end{array}$ & $\begin{array}{l}13 \\
(35.1)\end{array}$ & $\begin{array}{l}59 \\
(41.0)\end{array}$ & $\begin{array}{l}23 \\
(46.9)\end{array}$ & $98(41.4)$ & \\
\hline
\end{tabular}




\begin{tabular}{|l|l|l|l|l|l|l|}
\hline & Ne znam & $\begin{array}{l}2 \\
(28.6)\end{array}$ & $9(24.3)$ & $\begin{array}{l}40 \\
(27.8)\end{array}$ & $\begin{array}{l}17 \\
(34.7)\end{array}$ & $68(28.7)$ \\
\hline $\begin{array}{l}\text { Ukupno ispitanika prema finansijskoj situaciji } \\
\text { (N) i postotak (\%) }\end{array}$ & $37(100)$ & $\begin{array}{l}144 \\
(100)\end{array}$ & $\begin{array}{l}49 \\
(100)\end{array}$ & $237(100)$ \\
\hline
\end{tabular}

*statistički značajno na nivou $\mathrm{p}<0.05$

Ispitanici sa lošom finansijskom situacijom statistički značajno $(p=001)$ više konzumiraju cigarete $u$ odnosu na učenike koji su u porodicama sa dobrom i odličnom finansijskom situacijom (Tabela 5).

Tabela 5. Odnos broja konzumiranih cigareta mjesečno i finansijske situacije u porodici

\begin{tabular}{|c|c|c|c|c|c|c|c|}
\hline \multirow[b]{3}{*}{ Pitanje } & \multirow[b]{3}{*}{$\begin{array}{l}\text { Ponuđeni } \\
\text { odgovori }\end{array}$} & \multicolumn{4}{|c|}{ Finansijska situacija u porodici } & \multirow{3}{*}{$\begin{array}{l}\text { Ukupno ispitanika prema } \\
\text { odgovorima }(\mathrm{N}) \text { i postotak }(\%)\end{array}$} & \multirow[b]{3}{*}{$\mathbf{p}^{*}$} \\
\hline & & Loša & Osrednja & Dobra & Odlična & & \\
\hline & & $\mathbf{N}(\%)$ & $\mathbf{N}(\%)$ & $\mathbf{N}(\%)$ & $\mathbf{N}(\%)$ & & \\
\hline \multirow{7}{*}{ 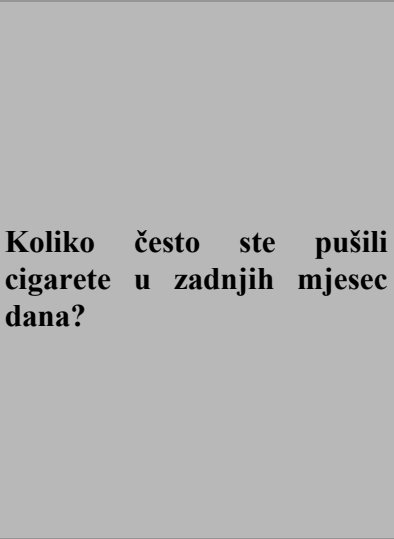 } & Ni jednom & $\begin{array}{l}4 \\
(57.1)\end{array}$ & $28(71.8)$ & $\begin{array}{l}132 \\
(88.0)\end{array}$ & $\begin{array}{l}42 \\
(84.0)\end{array}$ & $206(83.7)$ & \multirow{8}{*}{.001} \\
\hline & $\begin{array}{l}1 \text { cigareta } \\
\text { mjesečno }\end{array}$ & $0(0.0)$ & $2(5.1)$ & $3(2.0)$ & $1(2.0)$ & $6(2.4)$ & \\
\hline & $\begin{array}{l}1 \\
\text { sedmično }\end{array}$ & $0(0.0)$ & $0(0.0)$ & $0(0.0)$ & $2(4.0)$ & $2(0.8)$ & \\
\hline & $\begin{array}{lll}1 & -5 & \text { cigareta } \\
\text { dnevno } & \end{array}$ & $0(0.0)$ & $2(5.1)$ & $4(2.7)$ & $0(0.0)$ & $6(2.4)$ & \\
\hline & $\begin{array}{lrr}6 & -10 & \text { cigareta } \\
\text { dnevno }\end{array}$ & $\begin{array}{l}3 \\
(42.9)\end{array}$ & $2(5.1)$ & $5(3.3)$ & $2(4.0)$ & $12(4.9)$ & \\
\hline & $\begin{array}{lll}11 & -20 & \text { cigareta } \\
\text { dnevno }\end{array}$ & $0(0.0)$ & $4(10.3)$ & $5(3.3)$ & $1(2.0)$ & $10(4.1)$ & \\
\hline & $\begin{array}{l}\text { Više od } 20 \\
\text { cigareta dnevno }\end{array}$ & $0(0.0)$ & $1(2.6)$ & $1(0.7)$ & $2(4.0)$ & $4(1.6)$ & \\
\hline \multicolumn{2}{|c|}{$\begin{array}{l}\text { Ukupno ispitanika prema finansijskoj situaciji } \\
\text { (N) i postotak (\%) }\end{array}$} & $\begin{array}{l}7 \\
(100)\end{array}$ & $39(100)$ & $\begin{array}{l}150 \\
(100)\end{array}$ & $50(100)$ & $246(100)$ & \\
\hline
\end{tabular}

*statistički značajno na nivou $\mathrm{p}<0.05$

\section{DISKUSIJA}

Rezultati našeg istraživanja su pokazali da $16.09 \%$ učenika JU Gimazija „Jovan Dučić“ u Doboju konzumira cigarete. Veća prevalencija pušača je među adolescentima muškog pola, što je u saglasnosti sa rezultatima istraživanja $u$ drugim zemljama $(10,11)$. Naše istraživanje je pokazalo da učenici, čiji prijatelji puše, statistički značajno $(\mathrm{p}=$ 0.000) češće konzumiraju cigarete $u$ odnosu na učenike čiji su prijatelji i roditelji nepušači. Rezultati drugih istraživanja su takođe pokazali značajan uticaj prijatelja i porodice, koji puše, na početak pušenja adolescenata (10-12).

Rezultati našeg istraživanja su pokazali da finansijska situacija porodice nije statistički značajno uticala na započinjanje pušenja kod naših ispitanika. Rezultati drugih istraživanja su pokazali da postoji pozitivna povezanost između bruto domaćeg proizvoda $i$ šanse mlade osobe $u$ niskorazvijenim i srednjerazvijenim zemljama da postanu pušači. Isto istraživanje je pokazalo da povećanje domaćeg bruto proizvoda za $10 \%$ povećava šanse za početak pušenja za $2.5 \%$ ili više (13).

Istraživanja u drugim zemljama pokazala su različite rezultate o zastupljenosti pušenja kod adolescenata. Tako je istraživanje provedeno $u$ Sjedinjenim Američkim Državama (SAD) pokazalo da kod učenika srednjih škola i studenata na fakultetima $20 \%$ je probalo cigarete, $8.5 \%$ su povremeni pušači dok redovno puši $4 \%$ ispitanika (10). Rezultati istraživanja, provedenog u Južnoj Aziji (Pakistan, Indija, Bangladeš i Nepal) su pokazali da je zastupljenost pušača kod školske djece $5.4 \%$, što je značajno manje nego u našem istraživanju (11). Istraživanje je pokazalo predominaciju pušača muškog pola, što se slaže sa rezultatima našeg istraživanja. Veliko istraživanje o zastupljenosti pušenja kod adolescenata, provedeno 1994.godine i 2007. godine, pokazalo je porast broja pušača među adolescentima sa $21.2 \%$ na $27.9 \%$. Procenat adolescenata pušača se povećao kod 
ispitanika muškog pola sa $20.5 \%$ na $30.3 \%$, a kod ispitanika ženskog pola sa $12.2 \%$ na $21.7 \%$ (14).

Prosječno oko $90 \%$ osoba koje puše su započele sa pušenjem u adolescentnoj dobi, kada su bili mlađi od 18 godina, a veliki broj osoba koje su probale cigarete $\mathrm{u}$ adolescentnom uzrastu su postali redovi pušači. Identifikovani su i drugi faktori rizika, koji su povezani sa upotrebom cigareta, kao što su istovremena upotreba alkohola $\mathrm{i}$ droga, pušenje sa prijateljima i porodicom. Kao i upotreba alkohola, pušenje često prethodi drugim načinima zloupotrebe supstanci (15). Zbog svega navedenog, neophodno je provođenje mjera za ranu prevenciju pušenja. $U$ zemljama, u kojima su organizovane kampanje i preventivni programi, došlo je do značajnog smanjenja broja pušača među adolescentima. Tako je u Norveškoj prevalencija pušača među adolescentima opala sa $15.5 \%(1993 / 1994)$ na $6.0 \%$ (2009/2010) (16).

Primarna zdravstvena zaštita je optimalno mjesto za implementaciju intervencija za prevenciju pušenja kod djece i adolescenata. Edukacija i interpesonalne diskusije zdravstvenih profesionalaca i članova porodica o rizicima pušenja i strategijama za izbjegavanje konzumiranja cigareta mogu smanjiti stopu pušača kod djece i adolescenata (17). Važan uticaj na smanjenje stope pušenja kod adolescenata ima i zabrana reklamiranja cigareta te smanjenje broja prodavaca cigareta u okolini škola. Kao važan faktor rizika za pušenje kod adolescenata navodi se i pušenje kod autoriteta (18). Osim ljekara, medicinske sestre u ambulantama, školske medicinske sestre i patronažne medicinske sestre mogu imati važnu ulogu u prevenciji pušenja kod adolescenata. Studija, provedena kod školske djece u Rumuniji, pokazala je da edukacija o štetnostima pušenja u školama, kod adolescenata dobi 14 do 15 godina, ima značajne rezultate u prevenciji pušenja kod adolescenata (19). U današnjem vremenu, kada elektronski mediji i internet zauzimaju značajno mjesto u životu svih ljudi, a posebno adolescenata, pokazalo se da poruke o štetnostima pušenja upućene putem ovih medija, mogu dati značajne rezultate u prevenciji pušenja kod adolescenata (20).

\section{ZAKLJUČAK}

Adolescenti su rizična grupa za početak upotrebe duvana. Većina osoba koje su u ovom životnom dobu započeli sa konzumiranjem cigareta održavaju ovu naviku i u odrasloj dobi. Timovi porodične medicine bi trebalo da posvete veću pažnju u prevenciji pušenja, posebno kod ove osjetljive populacije.

\section{LITERATURA}

1. Jakovljević M. Izabrana poglavlja iz psihološke medicine.U: Vrhovac B i sur. Interna medicina, Naklada Ljevak, Zagreb; 2003.str. 1635- 51.

2. Defans - Gojanović M. Patoanatomski nalaz u ovisnika. U: Lacković Z. (ur.). Nove spoznaje o farmakologiji droga. Medicinska naklada, Zagreb; 2002. str. 3-36.

3. Lacković Z. Duhan. U: Lacković Z.(ur.) Nove spoznaje o farmakologiji droga. Medicinska naklada, Zagreb; 2002.str. 65-80.

4. Stanetić K. Pušenje. U: Stanetić K. (ur.) Prevencija u radu porodičnog ljekara. Narodna i univerzitetska biblioteka Republike Srpske. Banja Luka; 2015: str. 13-31.

5. Hrabak- Žerjavić V. Pušenje - čimbenik rizika za zdravlje. U: Hrabak- Žerjavić V. (ur.) Pušenje kao javni problem. Hrvatski zavod za javno zdravstvo. Zagreb; 2007: str. 3-11.

6. Katić M. Djelovanje u zajednici. U: Katić M. (ur.) Obiteljska medicina. Naklada Alfa. Zagreb; 2013: str. 371-413.

7. Dakić- Dejanović S, Milovanović D. Bolesti zavisnosti. U: Dakić-Dejanović S. (ur.) Farmakoekonomija liječenja zavisnosti. Medicinski fakultet. Kragujevac; 2002: str. 1-26.

8. Guttormsson HB . U: A supplement to the 2011 ESPAD Repert. The Swedish Council for Information on Alcohol and Other Drugs. Council of Europe. Thee European Monitoring centar for Drugs and Drug Adiction. Pompidum Group. Stocholm; 2013.

9. www.phi.rs.ba/pdf/publikacije/espad-2008-

sr.pdf.evropsko /Istraživanje o upotrebi droga, duvana i alkohola među srednjoškolcima/ [pristupljeno 27.03.2019]

10. Yu M, Chavez PE, Olate R, Peters C. Cigarette Smoking Status Among Latino/Hispanic Midle and High School Students in the United States. Subst Use Misuse. 2017;23;52(3):303-12.

11. Rao S, Aslam SK, Zaheer S, Shafique K. Antismoking initiative and current smoking among 19,643 adolescents in South Asia: findings from the Global Youth Tabacco Survey. Harm Reduct J.2014;25;11:8. 
12. Soh JH, Jung YK, Jang GY, Shin YK, Lee KH, Eun $\mathrm{BL}$, et al. Predisponing factors of risk taking behaviors in Korean adolescents. J Korean Pediatr Soc.2001;44:1364-73.

13. Li DX, Guinondon GE. Income, income inequality and youth smoking in low- and middle-inome countries. Addiction. 2013;108(4):799-808.

14. Tucker JS, Ellickson PL, Klein DJ. Predictors of the transition to regular smoking during adolescence and young adulthood. J Adolesc Health. 2003;32:314-24.

15. Aslam SK, Zaheer S, Rao S, Shafique K. Prevalence and determinates of suscetibility to cigarette smoking among school students in Pakistan: secundary analysis of Global Youth Tabacco Survey. Sust Abuse Treat Prev Policy.2014;9:10.

16. Braverman NT, Stawski RS, Samdal O, Aaro LE. Daily Smoking and Subjective Health Complaints in Adolescence. Nicotine Tob Res. 2017;19(1):102110 .
17. Duncan LR, Pearson ES, Maddison R. Smoking prevention in children and adolescents: A systematic review of individualized interventions. Patient Educ Couns.2018;101(3):375-88.

18. Gwon SH, Yan G, Huang G, Kulbok PA. The influenze of tabacco retailers on adolescent smoking: prevention and policy implications. Int Nurs Rev.2018;65(2):234-43.

19. Lotrean LM, Loghin CR, Popa M, Vries HD. Smoking prevention for adolescents in Romanian schools. Asian Pac J Cancer Prev.2013;14(11):701721.

20. Mays D, Hawkins KB, Bredfeldt C, Wolf $\mathrm{H}$, Tercyak KP. The effects of framed messages for engaging adolescents with online smoking prevention interventions. Transl Behav Med. 2017;7(2):196-2013.

\begin{abstract}
Introduction: Abuse of tabacco in many countries of the world, as well as our country, takes epidemic proportions. It is particularly pronaunced in the youth population. According to data of World Health Organization (WHO) it is considered to be currently more than a billion smokers in the world.

Aim: to investigate smoking habits in the students of Gymnasium ,,Jovan Dučic “ Doboj and influenze of socioeconomic factors on tabacco use.

Methods: The study was conducted among students in Gymnasium „Jovan Dučić" Doboj in the period from March to May 2018. The research was anonymous. All students are offered two questionnaires: questionnair with sociodemographic data (sex, age, family status, education level of parents, financial situation of the family) and questionnaire about tabacco use.

Results: The study included 255 students, $38 \%$ male and $62 \%$ female. Out of total number of participants, $16.08 \%$ declared to consume cigarettes (14 female, 27 male). The majority of surveyed students began to consume cigarettes in age 16 and more (19 students, 46.34\%). Male, age 14-15 years, and those in age 16 and more, in a higher percentage consume cigerettes, in relation to female, what is statistically significant $(p=001)$. Students, whose friends are smoking, statistically significant $(p=$ 0.000) consume cigarettes more often in relation to those whose friends are non-smokers.

Conclusion: Adolescents are the risk group to start to use tabacco. Family medicine teams should pay more attention in the prevention of smoking, especially for this sensitive population.
\end{abstract}

Key words: smoking, adolescents, risk factors, prevention

Corresponding author:

Kosana Stanetić

Address: Vojvode Momcila 9/a, 78.000 Banja Luka

Bosnia and Herzegovina

email: stanetic.kosana@gmail.com

Tel: 0038765535790 